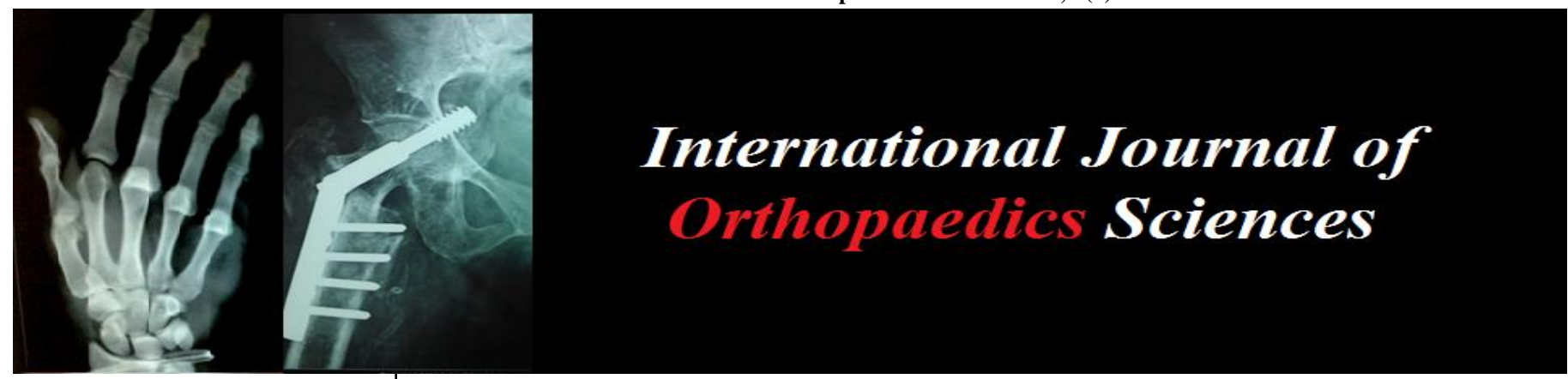

E-ISSN: 2395-1958

P-ISSN: 2706-6630

IJOS 2020; 6(2): 587-588

(C) 2020 IJOS

www.orthopaper.com

Received: 04-02-2020

Accepted: 06-03-2020

Dr. Randhi Rama Kartheek Consultant Sai Krishna Hospital Gandhinagar 4, Srungavarapukota Vizianagaram, Andhra Pradesh, India

Dr. T Bavani Prasad

Consultation, Vishaka Orthopedic Vizag, Andhra Pradesh, India

Dr. Nagireddi Ravi Shankar Resident, MIMS Vizianagaram, Andhra Pradesh, India

Dr. Bandela Manoranjan Resident, MIMS Vizianagaram, Andhra Pradesh, India
Corresponding Author:

Dr. Randhi Rama Kartheek

Consultant Sai Krishna Hospital Gandhinagar 4, Srungavarapukota Vizianagaram, Andhra Pradesh, India

\section{Acute distal radius epiphyseal osteomyelitis in a 12year old boy presented as an impending compartment syndrome: A case report}

\author{
Dr. Randhi Rama Kartheek, Dr. T Bavani Prasad, Dr. Nagireddi Ravi \\ Shankar and Dr. Bandela Manoranjan
}

DOI: $\underline{\text { https://doi.org/10.22271/ortho.2020.v6.i2j.2104 }}$

\section{Abstract}

A 12-year-old boy developed acute epiphyseal osteomyelitis of the distal radius following a fall. Despite a delay of 6days for the diagnosis, the patient was successfully treated with surgery and antibiotics. Clinical examination, complete blood count, erythrocyte sediment rate were crucial for the differential diagnosis, and intraoperative findings were the definitive diagnosis.

Keywords: Radial, epiphyseal, osteomyelitis, impending compartment syndrome

\section{Introduction}

Epiphyseal osteomyelitis in children is a rare entity with severe consequences.

We discuss the case of a 10-year-old boy who presented to us with a history of fall and tenderness at distal radius followed by impending compartment syndrome within seven days of the fall. For which we have done compartment release found pus. We discuss the presentation diagnosis and treatment, and outcome.

\section{Case presentation}

History, clinical features and investigations

A previously well 10 years old boy from a rural area came to OPD with a painful swollen right wrist following a witnessed fall from tree two days before the presentation. He was treated with native treatment by massage and application of cold cloth. He is complaining of pain and distal radius, and he is not using it as it is paining. He has pain tenderness at the distal radius he can do flexion, extension, pronation and supination with a little pain. X-ray shows a fracture in scaphoid, but the patient has no signs of it. Applied blow elbow posterior slab and sent home. The patient visited OPD after three days complaining of fever and increased pain. Radiographs were repeated; there is no change in the radiographs. As there is local raise of temperature and tenderness at the extensor compartment advised complete blood count, which showed leucocytosis of 18,000/cc. Advised I.V antibiotics ceftriaxone and sulbactam of $100 \mathrm{mg} / \mathrm{kg}$ bid and amikacin $15 \mathrm{mg} / \mathrm{kg}$. The patient visited opd after three days with no symptoms, but clinically there is an impending compartment syndrome with a normal pulse and decreased finger movements. Total leucocyte count showed leucocytosis of 22,000/cc. Advised surgery (compartment release).

\section{Operative findings and outcome}

Under brachial plexus block, first flexor compartment is released no significant intraoperative findings. Then extensor compartment was released along the third compartment. The abnormal irregular structure was palpable at the distal end of the radius at the ulnar border of radial epiphysis. When the extensor compartment was released, the pus of $100 \mathrm{ml}$ was obtained, and discharge was sent for culture sensitivity. The patient was on empirical treatment with amikacin and piperacillin-tazobactam until the reports have arrived. The patient has developed the next day after the surgery clinically. 
The complete blood count on the next day ( $1^{\text {st }}$ POD) was $17000 / \mathrm{cc}$, and ESR was $60 \mathrm{~mm}$ and on $3^{\text {rd }}$ POD was $22000 / \mathrm{cc}$ with ESR of $106 \mathrm{~mm}$. Culture sensitivity has reported Staphylococcus aureus and sensitive to Linezolid. The patient was started with oral Lenizolid $600 \mathrm{mg}$ BID and oral Clindamycin 300mg BID. After three days ( $5^{\text {th } P O D), ~ t h e ~ T L C ~}$ was $9000 / \mathrm{cc}$, and ESR was $50 \mathrm{~mm}$. Clinically patient was well with a good range of motion of fingers.

\section{Discussion}

Epiphyseal haematogenous osteomyelitis (HOM) is an uncommon condition, usually subacute but occasionally acute in which infection can spread, or it may land up in compartment syndrome if not detected promptly ${ }^{[1]}$. Most cases of epiphyseal HOM occur around the knee ${ }^{[2]}$. Though there has been a report of osteomyelitis of the proximal radial epiphysis, we have not been able to find a report of acute distal radial HOM ${ }^{[3]}$. Bone injury and trauma may have predisposed the tissue to develop an infection after bacteraemia.
Experiments in a rabbit tibial trauma model have demonstrated this Morrissy and Hayness ${ }^{[4]}$ compared physeal injuries in rabbits, one group, with now injuries but with a deliberate bacteriemia another group with injuries but without bacteraemia and the last group with both the injuries and bacteraemia. It described that physeal injuries without bacteraemia healed within 7days, those without injuries but with a deliberate bacteraemia developed only a small focus of osteomyelitis. In contrast, those with both wounds and bacteraemia developed significant osteomyelitis.

Regular clinical examination, complete blood count and ESR can be used for disease prognosis in a rural setup where MRI and bone scan is not available. In our case, the exact cause of HOM cannot be determined. It is likely precipitated by trauma.

\section{Conclusion}

- We have a reported a rare case of acute HOM of the distal radial epiphysis in a child.

- It is uncommon to diagnose osteomyelitis in an occult fracture with impending compartment syndrome.

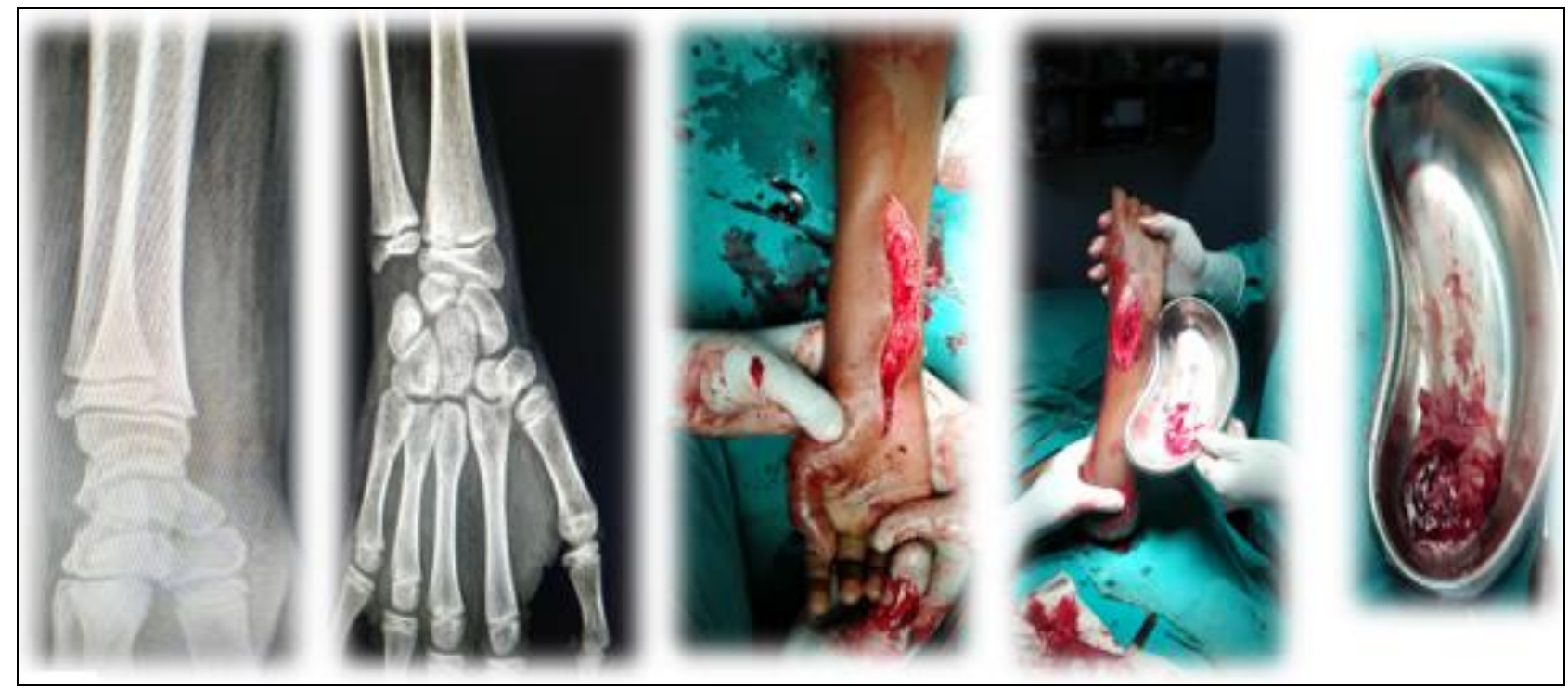

Fig 1: A rare case of acute HOM of the distal radial epiphysis in a child

\section{References}

1. Longion DB, Zionts LE, Stott NS. Acute hematogenous osteomyelitis of the epiphysis. Clin orthop Relat Res $1995 ; 316: 227-234$.

2. Sorensen TS, Hedeboe J, Christensen ER. Primary epiphyseal osteomyelitis in children. J Bone Joint Surg 1988; 70-B:818-820

3. Maffulli N, Fixsen JA. Osteomyelitis of the proximal radial epiphysis. A case report. Acta Orthop Scand 1990; 61(3):269-270.

4. Morrissy RT, Haynes DW. Acute hematogenous osteomyelitis: A model with trauma as an eitiology. J Paediatr Orthop. 1989; 9:447-456. 